\title{
Application of PSCF and CWT to Identify Potential Sources of Aerosol Optical Depth in ICIPE Mbita
}

\author{
Misiani Zachary ${ }^{1,2 *}$, Lun Yin ${ }^{3}$, Mwai Zacharia ${ }^{1,2}$ \\ ${ }^{1}$ School of Atmospheric Sciences, Nanjing University of Information Science and Technology, Nanjing, China \\ ${ }^{2}$ Kenya Meteorological Department, Ministry of Environment \& Forestry, Nairobi, Kenya \\ ${ }^{3}$ Yunnan Academy of Social Sciences, Kunming, China \\ Email: *zacharymisiani@gmail.com
}

How to cite this paper: Zachary, M., Yin, L. and Zacharia, M. (2018) Application of PSCF and CWT to Identify Potential Sources of Aerosol Optical Depth in ICIPE Mbita. Open Access Library Journal, 5: e4487. $\underline{\text { https://doi.org/10.4236/oalib.1104487 }}$

Received: March 9, 2018

Accepted: April 17, 2018

Published: April 20, 2018

Copyright (C) 2018 by authors and Open Access Library Inc.

This work is licensed under the Creative Commons Attribution International License (CC BY 4.0).

http://creativecommons.org/licenses/by/4.0/

\section{(c) (i) Open Access}

\begin{abstract}
This paper evaluates the effects of long-range transport patterns of air trajectories arriving at a rural ground based station, ICIPE Mbita 1125 meters above mean sea level. Mass concentration data of fine mode AOD, coarse mode AOD and fine mode fraction AOD were combined with back-trajectory cluster analysis. The Potential Source Contribution Function (PSCF) model and Concentration-Weighted Trajectory (CWT) method were used to evaluate the transport pathways and Potential Source Areas (PSA) affecting AOD loadings in western parts of Kenya during wet (MAM) and dry (JJA) seasons. The main sources and paths of advection to source and receptor regions and its relation to AOD concentration were identified. Using these methods, the Geographic Information System (GIS) based software and MeteoInfo was used for query and computation of potential source contribution function and concentration weighted trajectory analyses when the measurement data were included. The results for both PSCF and CPF were sufficient indicators that pollutants originated from two main sources, that is, northeastern and southeast directions from the site.
\end{abstract}

\section{Subject Areas}

Environmental Sciences

\section{Keywords}

GIS, MeteoInfo, PSCF, CWT, PSA, MAM and JJA 


\section{Introduction}

The atmospheric aerosols usually occur in a bimodal distribution. The smaller part of these particles is referred to as the fine mode aerosols. They have a radii ranging between 0.1 to $0.25 \mu \mathrm{m}$, while the larger particles comprise of coarse mode aerosols. The larger particles generally have radii ranging between 1.0 to $2.5 \mu \mathrm{m}$, lastly, fine mode fraction aerosols which can be defined as the proportion of fine mode aerosols to the total. This is an optical measurement of the proportion by volume [1], [2].

The concentrations of atmospheric fine mode, coarse mode and fine mode fraction Aerosol Optical Depth (AOD) pollutants in western parts of Kenya are mainly affected by both local and regional source emissions. Statistical methods such as trajectory clustering and Potential Source Contribution Function (PSCF) for analyzing air-mass trajectories have been used to gain insights into the potential source areas (PSA) and prevail transport pathways for airborne particles and gases [3]. Trajectory clustering which is a multivariate statistical approach has been used as a tool for assigning trajectories into representative groups. [4] was the first to exploit trajectory coordinates as clustering variables, and various other clustering algorithms have been used in more recent studies [5].

PSCF method tends to give a good angular resolution but poor radial resolution because the trajectories converge as they approach the receptor. The concentration field method developed by [6] calculates the mean or geometric mean concentration of each grid cell which is then weighted by the residence time. [2] refined this method by redistributing the concentration fields, and [7] further refined it to a Concentration-Weighted Trajectory (CWT) method. The current paper uses AOD trajectories analysis data for wet and dry seasons from 2013 to 2015 to identify the potential source contribution function and concentration-weighted trajectory to examine and locate the main sources of air pollutants in the study area.

\section{Material and Methods}

\subsection{Area of Study}

The study AERONET ground station is located Longitude $34.2^{\circ} \mathrm{E},-0.417^{\circ} \mathrm{S}$, and 1125 meters above sea level, the red marked triangle shown in Figure 1 .

\subsection{Data for the Study}

The Fine Mode, Coarse Mode Aerosol Optical Depth (AOD), and Fine Mode Fraction AOD concentrations for ICIPE Mbita for wet and dry seasons for 2013, 2014 and 2015 were downloaded from AERONET Aerosol Robotic Network for level 2.0 daily averages, available at https://aeronet.gsfc.nasa.gov/new_web/index.html. 


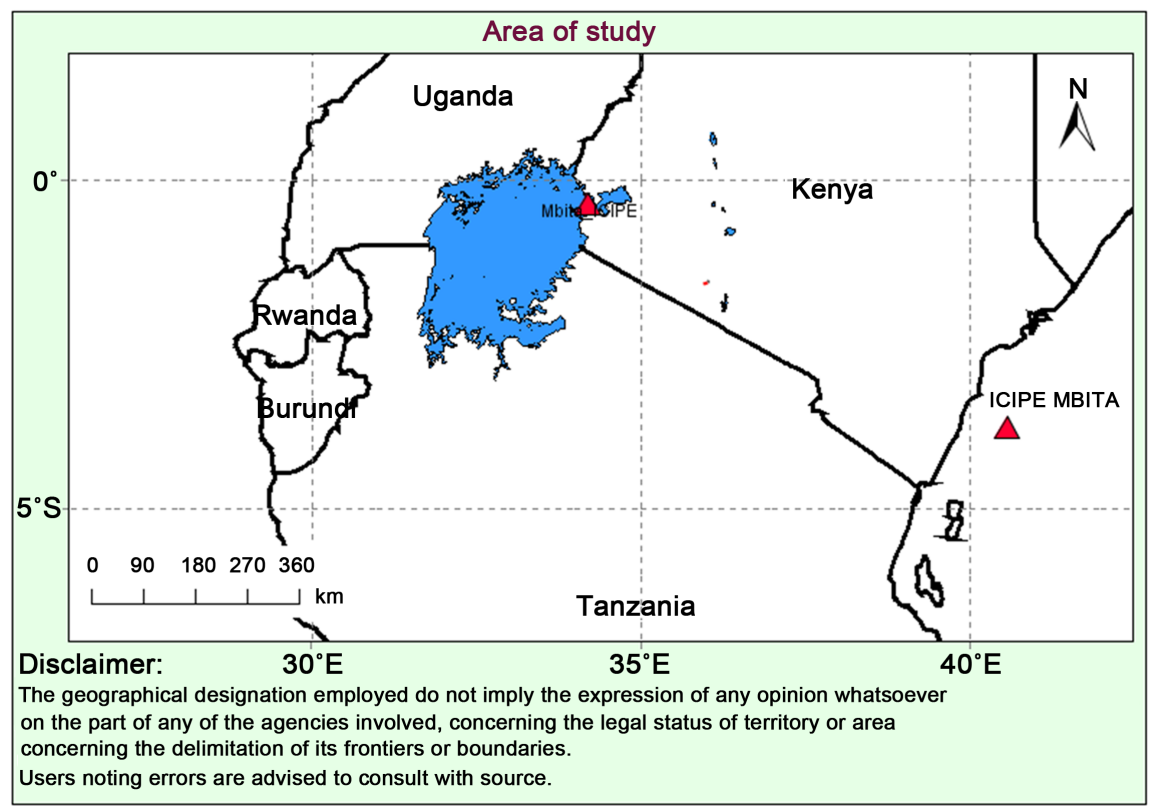

Figure 1. Map of the study area. The location marked with red triangle correspond to the ICIPE Mbita station. The areas shaded blue represent Lake Victoria surrounded by three countries; Kenya, Uganda and Tanzania.This map was produced on $5^{\text {th }}$ March 2018 by Misiani Zachary.

\section{The Methods Used in the Analysis}

\subsection{Trajectory Clustering}

In this study, Ward's hierarchical method was used to form the trajectory clusters for the wet and dry seasons combined, and this was based on calculating the mean angle between all pairs of trajectories. Angular distance was chosen in place of Euclidean distance mainly because the aim of this research work was to use the trajectories to determine the direction from which the air masses that reached the site had originated.

$$
d_{12}=\frac{1}{n} \sum_{i-1}^{n} \cos ^{-1}\left(0.5 \frac{\left(A_{i}+B_{i}-C_{i}\right.}{\sqrt{A_{i} B_{i}}}\right)
$$

where

$$
\begin{gathered}
A_{i}=\left(X_{1}(i)-X_{0}\right)^{2}+\left(Y_{1}(i)-Y_{0}\right)^{2} \\
B_{i}=\left(X_{2}(i)-X_{0}\right)^{2}+\left(Y_{2}(i)-Y_{0}\right)^{2} \\
C_{i}=\left(X_{2}(i)-X_{1}(i)\right)^{2}+\left(Y_{2}(i)-Y_{1}(i)\right)^{2}
\end{gathered}
$$

The variables $X_{0}$ and $Y_{0}$ define the position of the study site. Note that $d_{12}$ varies between 0 and $\pi$. The two extreme values occur when two trajectories are in the same and opposite direction, respectively. More details of the angle distance method are presented in [8].

The major transport pathways leading to the elevated AOD concentrations for ICIPE Mbita AERONET station during wet and dry seasons could be obtained 
by combining the trajectory with the daily fine mode, coarse mode and fine mode fraction concentration data (Figure 2).

In order to get faster details on how the aerosols are spatially distributed from the source point to the sinking site, $0.5^{\circ}$ by $0.5^{\circ}$ grid dimension was used for the analysis of PSCF. For more detailed information and faster analysis of the AOD, the $1^{\circ}$ by $1^{\circ}$ grid dimension was used for the WCT.

\subsection{Potential Source Contribution Function (PSCF).}

PSCF values are calculated to identify the source areas by analyzing trajectory transport pathways [9], [10]. To analyze possible long-range sources contributing to mean daily fine mode AOD, coarse mode AOD, and fine mode fraction AOD concentrations observed on this study area, a single grid cell was calculated by counting each trajectory segment endpoints that terminated within that grid cell. The number of endpoints that fall in $i j^{\text {th }}$ cell at a time was marked as $x_{i p}$ while the total number of endpoints that fall in the same grid cell was denoted as $y_{i j}[4]$. So the PSCF can be defined as

$$
P S C F_{i j}=x_{i j} / y_{i j}
$$

Thus, the PSCF values can be interpreted as a conditional probability describing the potential contributions of a grid cell to the high AOD loadings at ICIPE Mbita AERONET station. In this study, the criterion value was set to the mean concentration of all the AOD data. The study domain extends from $28^{\circ} \mathrm{E}$ to $50^{\circ} \mathrm{E}$ and from $15^{\circ} \mathrm{S}$ to $10^{\circ} \mathrm{N}$, thus composing 2200 cells $0.5^{\circ}$ by $0.5^{\circ}$ in latitude and longitude. To remove the uncertainty in cells with small values of $y_{i j}$ the PSCF values were multiplied by an arbitrary weight function $W_{i j}$ to better reflect the uncertainty in the values for these cells [3], [4], [11], [12]. The weighting function reduced the PSCF values when the total number of the endpoints in a particular cell was less than about three times the average value of the end points for each cell.

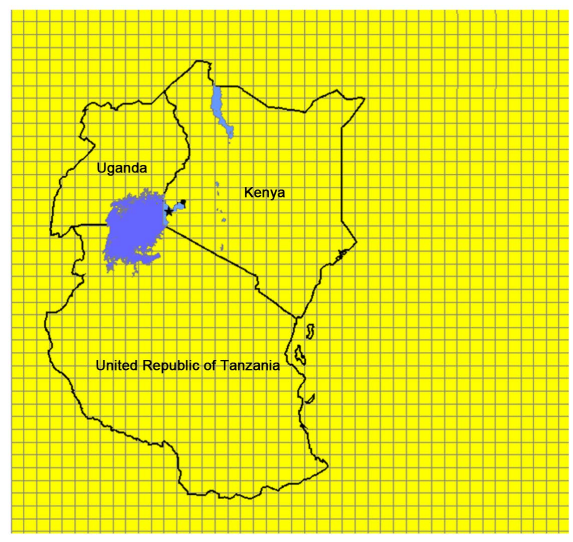

(a)

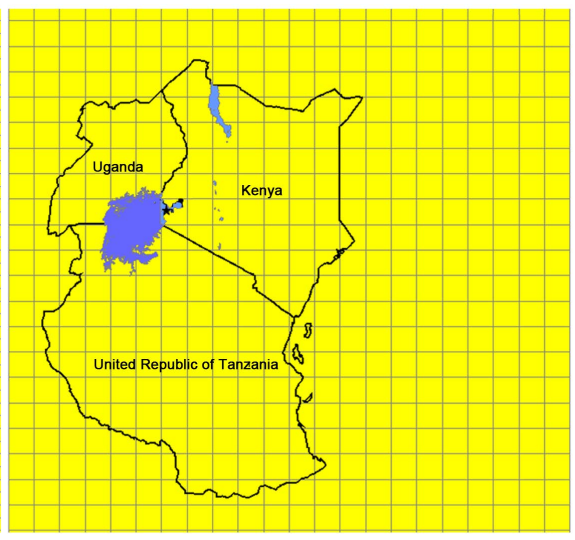

(b)

Figure 2. (a) Is grid points for PSCF $0.5^{\circ}$ by $0.5^{\circ}$ while (b) Is grid points for calculating CWT $1^{\circ}$ by $1^{\circ}$. 


$$
W_{i j}=\left\{\begin{array}{lc}
1.00, & 80 \leq n_{i j} \\
0.7, & 20<n_{i j} \leq 80 \\
0.42, & 10<n_{i j} \leq 20 \\
0.05, & n_{i j} \leq 10
\end{array}\right.
$$

\subsection{Concentration-Weighted Trajectory (CWT) Method.}

In order to avoid the laminations of the PSCF method whereby some grid cells could have the same PSCF value when sample concentrations could either be slightly higher or much higher than the criterion required as a result, it could be much more difficult to distinguish moderate sources from strong ones. Hence CWT method [8], [10], [13] was used with the aiming of producing a geographical overview of emission source areas within the study region.

$$
C_{i j}=\frac{1}{\sum_{l=1}^{M} \tau_{i j l}} \sum_{l=1}^{M} c_{l} \tau_{i j l}
$$

where $C$ is the average weighted concentration in the $i f^{\text {th }}$ cell, $l$ is the index of the trajectory, $M$ is the total number of trajectories, is the concentration observed on arrival of trajectory $l$, and is the time spent in the $i f^{\text {th }}$ cell by trajectory $l$. A high value for implies that air parcels traveling over the $i f^{\text {th }}$ cell would be, on average, associated with high concentrations at the receptor. The arbitrary weighting function described above was also used in the CWT analyses to reduce the effect of the small values of $n^{i j}$. For the CWT, study domain extends from $28^{\circ} \mathrm{E}$ to $50^{\circ} \mathrm{E}$ and from $15^{\circ} \mathrm{S}$ to $10^{\circ} \mathrm{N}$, thus composing 550 cells $1^{\circ}$ by $1^{\circ}$ in latitude and longitude.

\section{Results and Discussion}

In this present work, we have classified the data in terms of two major seasons, namely, wet (March-May) and dry (July-August) seasons which is based on synoptic winds and different meteorological conditions prevailing over Kenya.

\section{Regional Contributions}

Air mass residence time was analyzed by PSCF and CWT model, along with average daily concentrations of all the available fine mode AOD, coarse mode AOD and fine mode fractions, in order to isolate regional sources of particulate air pollution affecting the neighboring Kisumu city. The produced PSCF and CWT values were plotted on surface maps, presented in various figures below for both wet and dry seasons respectively.

Figure 3 shows the map for ICIPE Mbita AERONET Fine Mode AOD, Coarse Mode AOD and Fine Mode Fraction in MAM and JJA, 2013, 2014 and 2015 using PSCF method. The colors represent the contribution levels of PSA and the red color could be associated with high concentrations while the blue color represents low pollutants concentrations.

The map showing the results of the PSCF analysis Figure 3 and it could be 

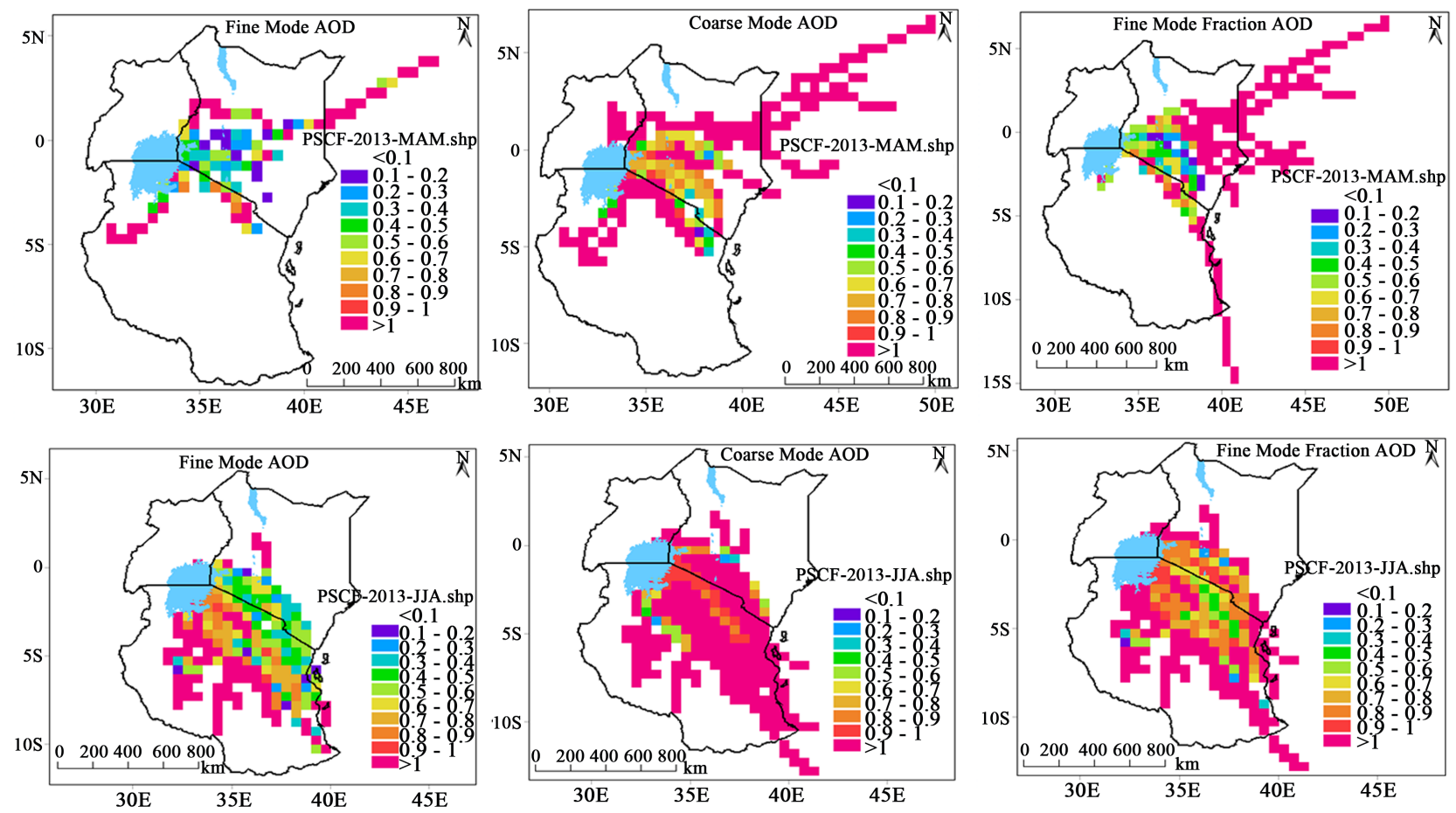

Figure 3. Potential source contribution function maps of Fine Mode AOD, Coarse Mode AOD and Fine Mode Fraction in MAM \& JJA seasons during 2013. Darker colors indicate greater potential source.

seen during wet period high WPSCF values were originating from the Northern Hemisphere [14] were found in Isiolo in eastern province, Wajir and Garissa in north eastern province and Samburu, Baringo, Laikipia and West Pokot of Rift valley province of Kenya. In JJA (dry season) the highest WPSCF values originates from the Southern Hemisphere were found in Makueni, Machakos and Kitui in eastern province, Kajiado in Rift valley, Nairobi and TaitaTaveta and Kwale in Coastal provinces of Kenya.

The results for fine mode AOD, coarse mode AOD and fine mode fraction concentrations identified by CWT method in Figure 4 were very similar to the results analyzed by PSCF method in Figure 3. The regions with red color, were corresponding to the main contributor sources associated with the highest AOD values. During this wet season, the highest WCWT values covering the map were distributed in central parts of Kenya including areas of Nairobi all the way through Rift valley to western province for coarse mode AOD. The fine mode AOD concentration is lower than coarse mode though for the fine mode fraction AOD its spatial coverage is on a wider spatial coverage than the fine mode and coarse mode AOD. These areas were the main contribution sources associated with the highest AOD concentrations.

In JJA (dry season), the high WCWT values were mainly located along all the counties bordering Kenya and Tanzania from Lake Victoria up to Indian Ocean. This demonstrated that the contribution from long-range transport and sources outside of ICIPE Mbita were significant for all of the above AOD.

In year 2014, the PSCF and CWT analyses from Figure 5 and Figure 6 gave 

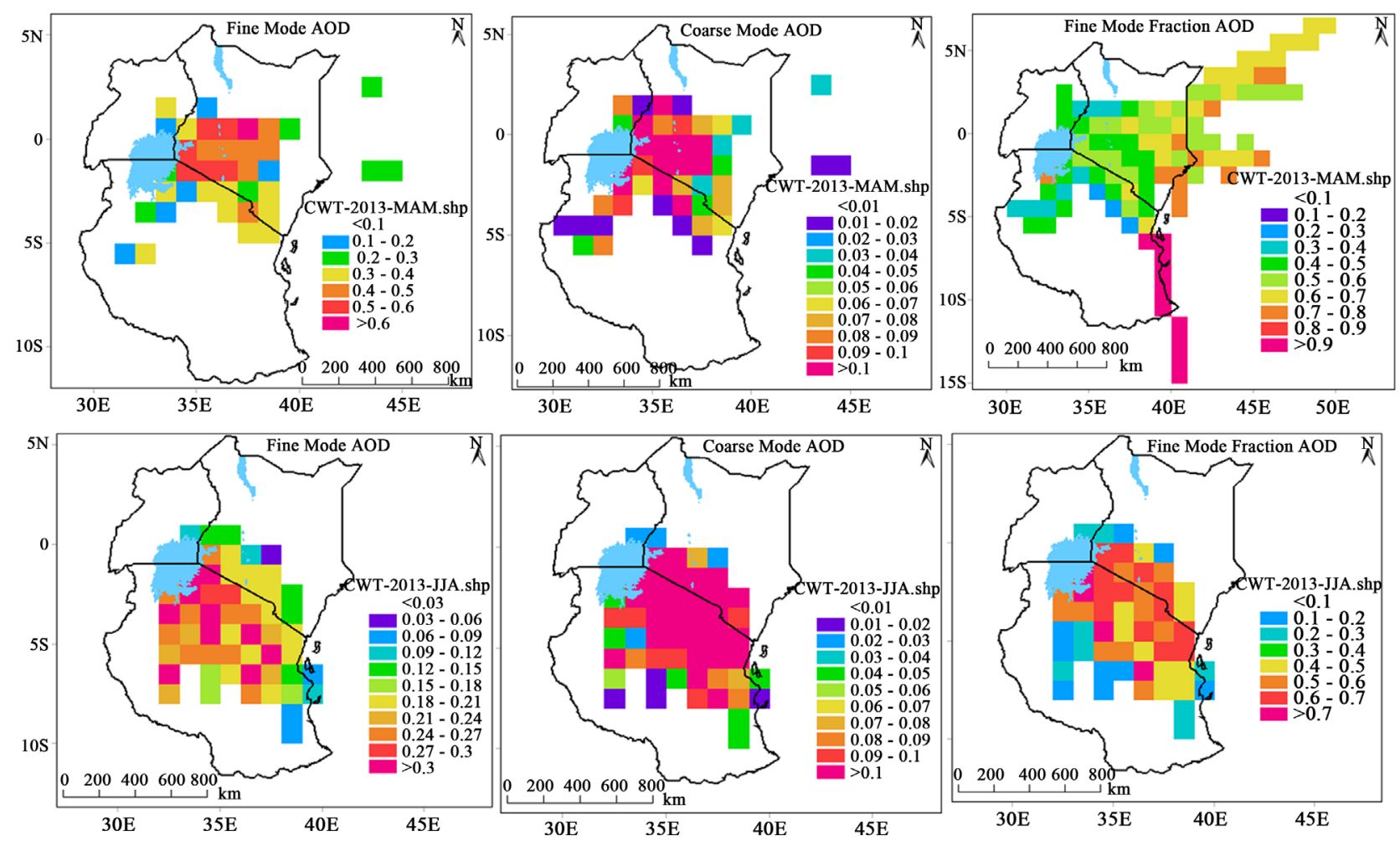

Figure 4. Concentration-weighted trajectory method analysis maps of ICIPE Mbita in MAM \& JJA during 2013. Darker colors indicate greater influence.
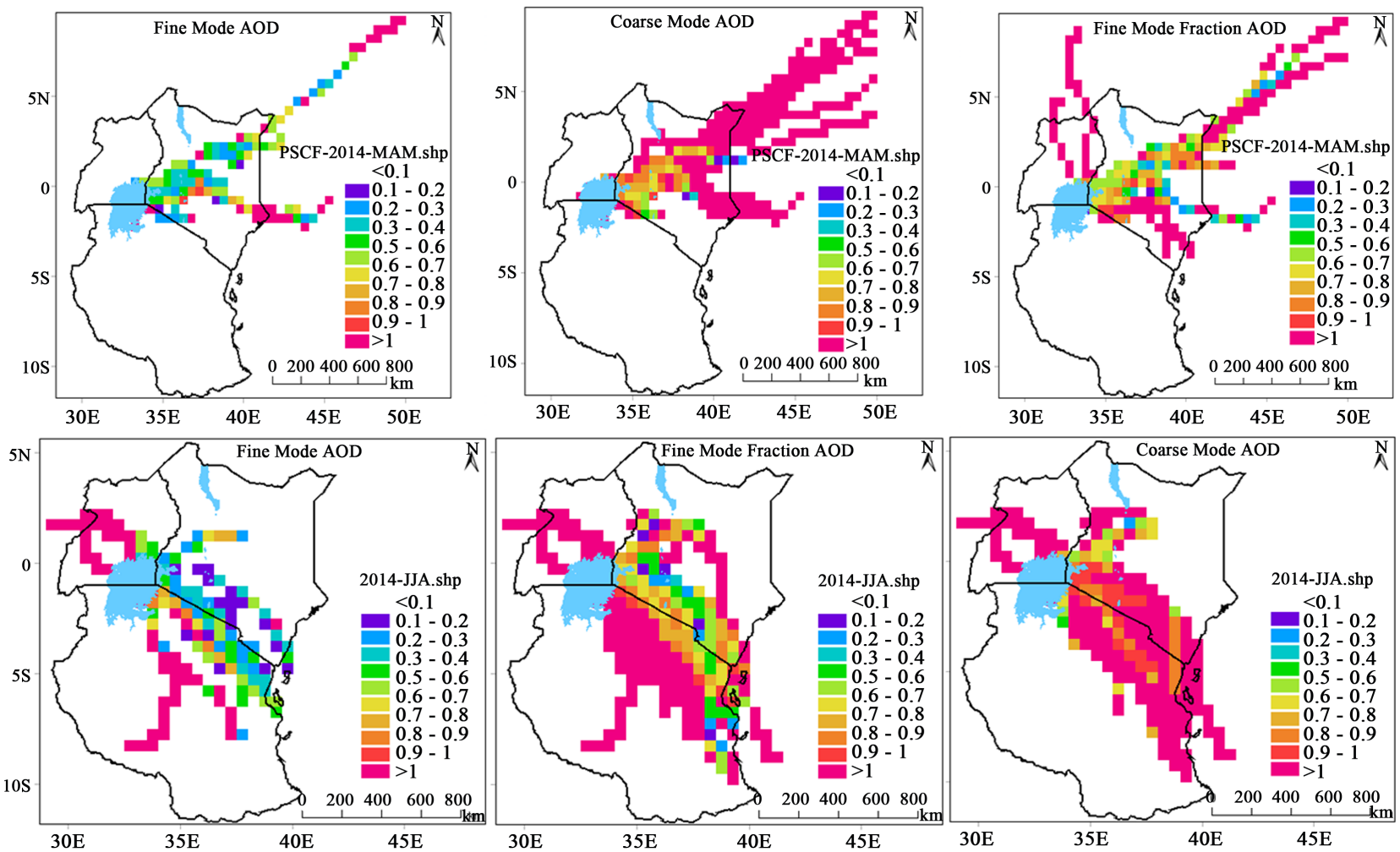

Figure 5. Potential source contribution function maps of Fine Mode AOD, Coarse Mode AOD and Fine Mode Fraction in MAM \& JJA seasons during 2014. Darker colors indicate greater potential source. 

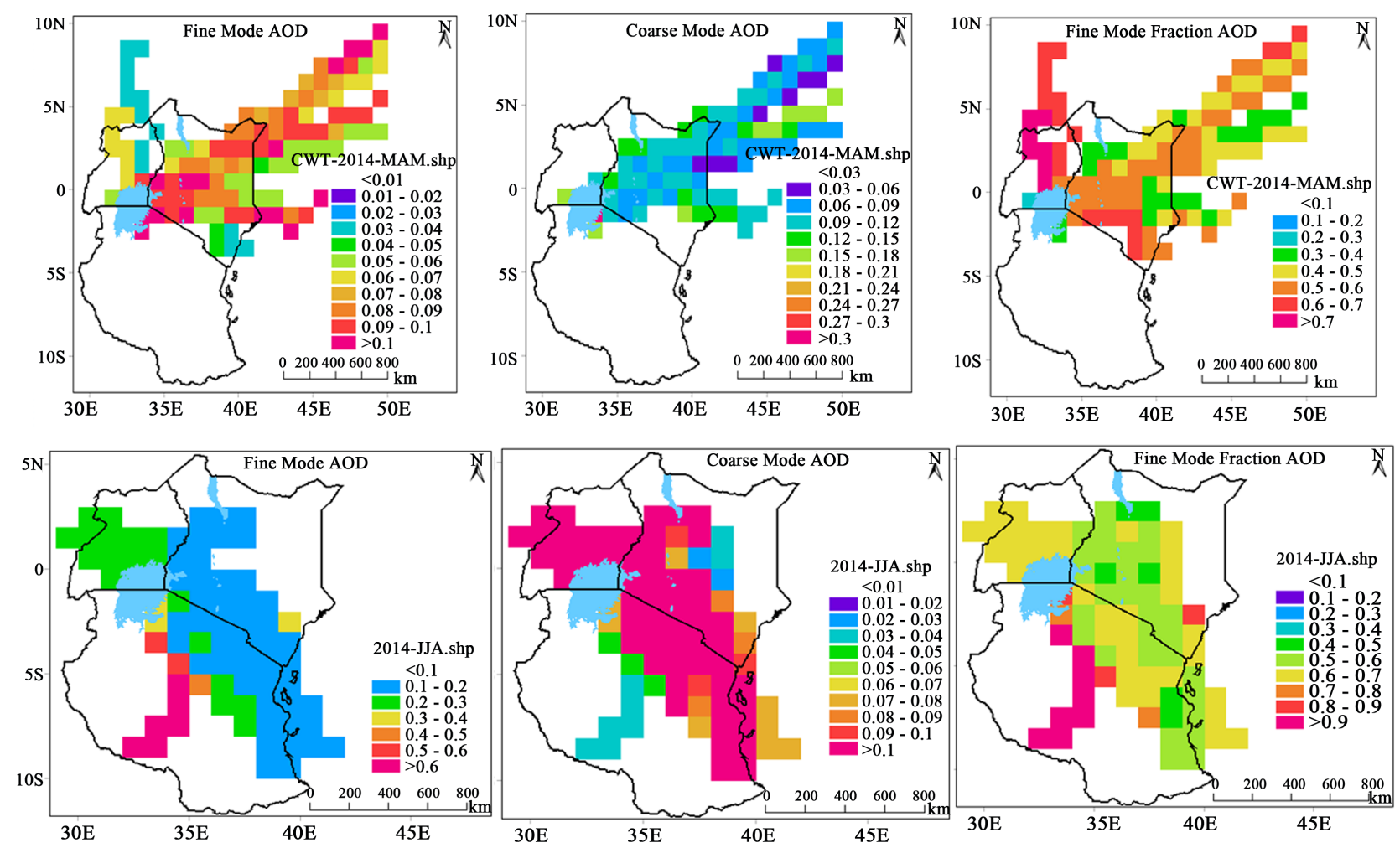

Figure 6. Concentration-weighted trajectory method analysis maps of ICIPE Mbita in MAM \& JJA during 2014. Darker colors indicate greater influence.

somewhat the same results for ICIPE Mbita. From the distribution of PSCF values Figure 5 one can see that the sources of AOD which affected Mbita during wet season were located in the North eastern and some of the coastal and eastern provinces of Kenya. These regions are mainly arid and semi-arid which comprises of Mandera, Wajir, Tana River, and Marsabit. While in JJA (dry season), from both figures we can see that much of the aerosols are concentrated on the southern parts of Kenya especially the border between Kenya and Tanzania. This shows a clear indication that the most aerosols originate from the Madagascar Island while others were locally pollinators [14].

From Figure 6, during wet season, it can be observed that most aerosols concertation originated from northeastern direction (Somalia land), Figure 6, fine mode AOD was ranging from 0.03-0.1 while 6 coarse modes it ranges from 0.03-0.18 and lastly fine mode fraction the values were ranging from 0.3-0.7. Fine mode Fraction AOD were more dominate among the other AOD. As the season changes to dry, the direction of AOD JJA also changes, most AOD arrived on the ICIPE Mbita were coming from southeast direction especially along the border of Kenya and Tanzania. Coarse mode AOD was with the highest values.

From Figure 8, in year 2015, it can be observed from both wet and dry season, that mostly AOD were coming from both NE and SE direction which led to an increasing amount of AOD concertation to our areas of interest. Due to the 
convergence of north easterlies and south eateries winds which acts as agents of transportation of aerosols along the equatorial region, it can be seen that the spatial distribution of aerosols was more than Figure 6.

Lastly for Figure 7 and Figure 8, both Potential source contribution function maps and Concentration-weighted trajectory maps showed large spatial coverage of the aerosol distribution when compared for the year 2013 and 2014. Same maps also indicate the same source of the aerosols which are transported to Kenya from various parts of the world.

\section{Conclusions}

The potential source regions with its relative contribution to high AOD loadings for ICIPE Mbita site were identified by potential source contribution function model, and concentration-weighted trajectory method. The PSCF method which is mainly focused on sources identification by using backward trajectory analysis to calculate and describe possible source locations was compared with CWT method which distinguishes the source strength more easily by assigning the concentrations values at the receptor site to their corresponding trajectories. Meteoinfo and ArcGIS tools were used for calculating PSCF and CWT concentrations. The use of GIS in data analysis provided a greater advantage. GIS tools used in this research study made the analyses easier. Through this research, the use of GIS in monitoring aerosols pollutants source identification is expanded.
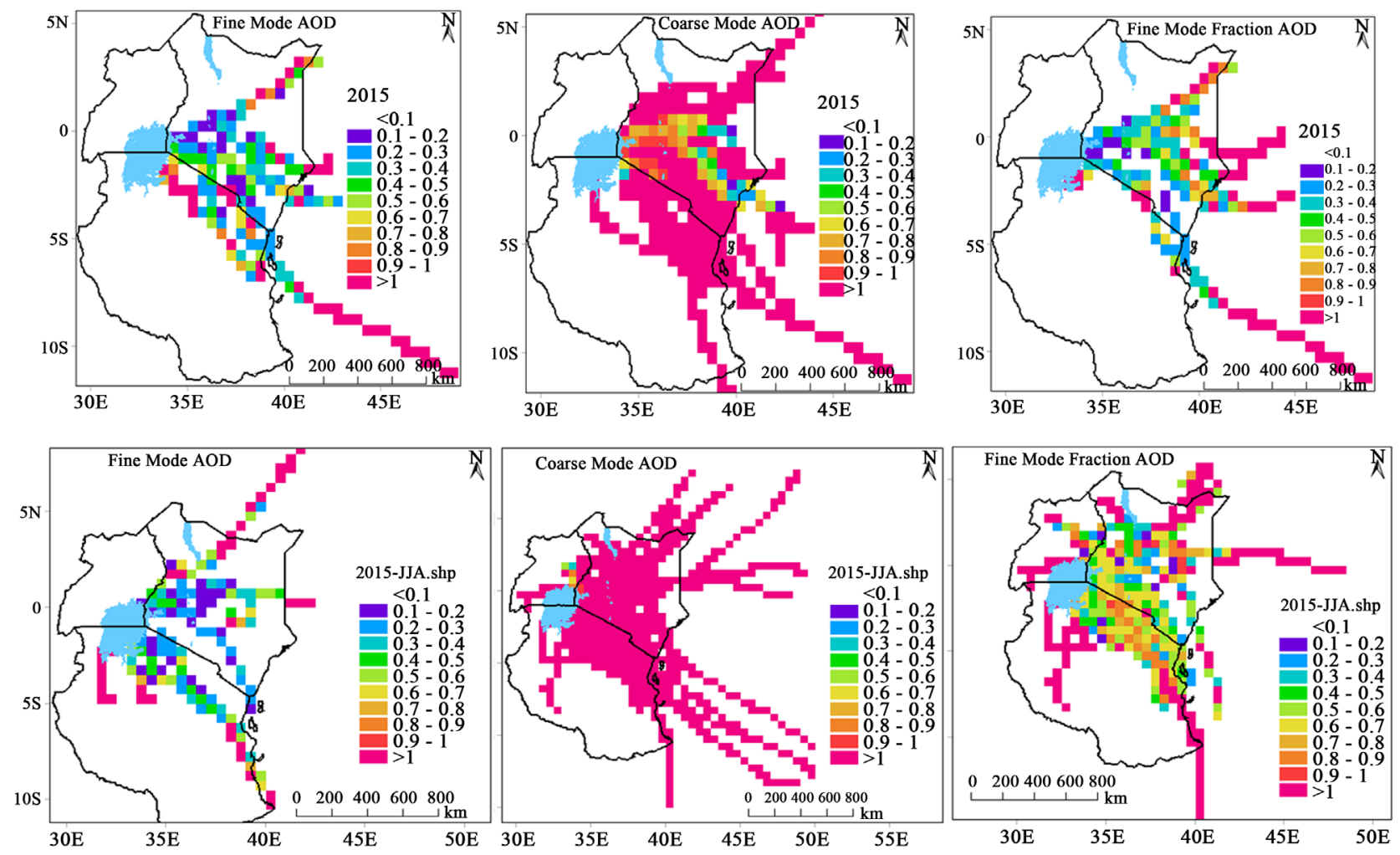

Figure 7. Potential source contribution function maps of Fine Mode AOD, Coarse Mode AOD and Fine Mode Fraction in MAM \& JJA seasons during 2015. Darker colors indicate greater potential source. 

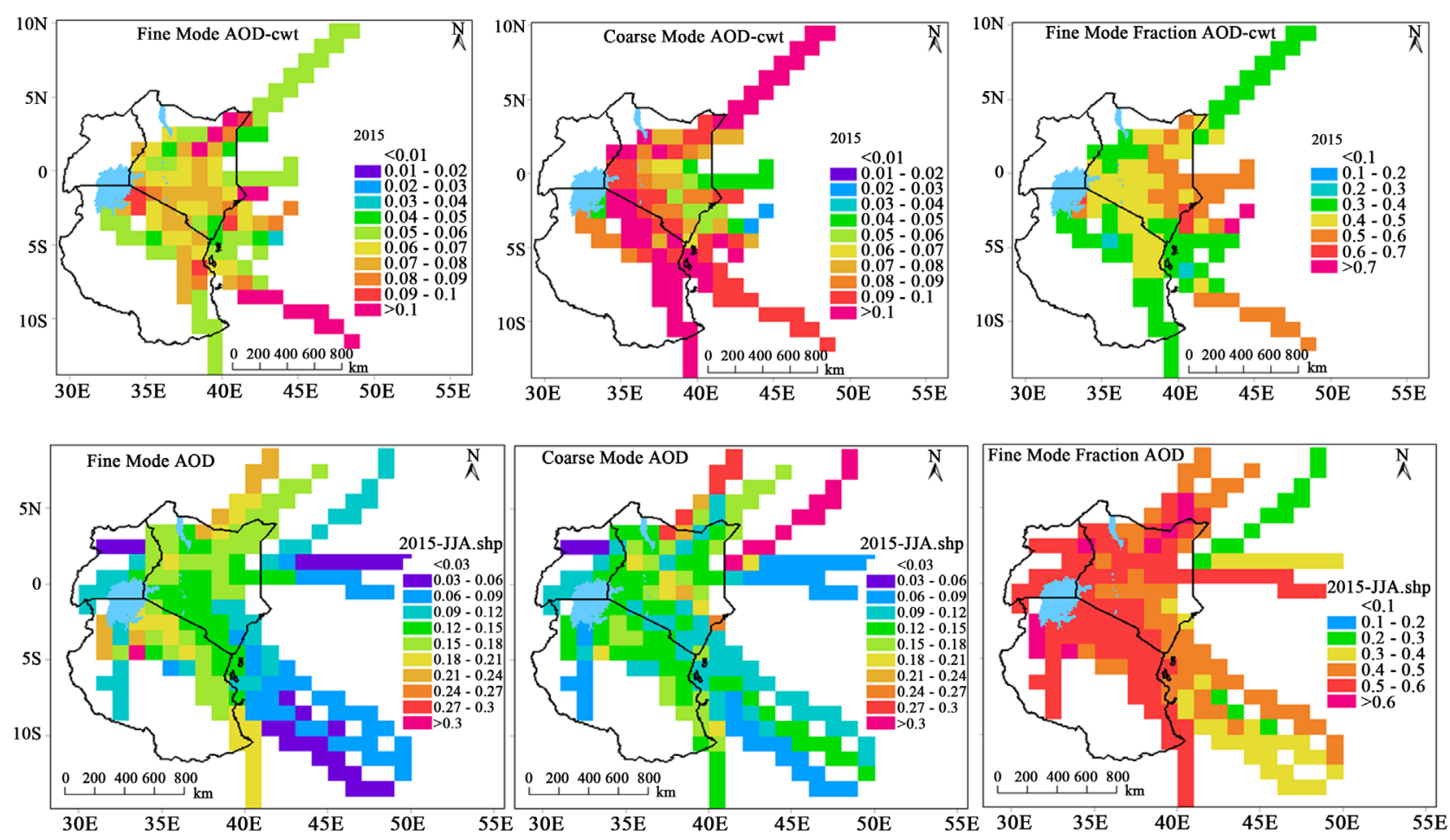

Figure 8. Concentration-weighted trajectory method analysis maps of ICIPE Mbita in MAM \& JJA during 2015. Darker colors indicate greater influence.

Both PSCF and CWT methods produced a good agreement of pollutants concentrations from the receptor areas. The grid-based difference in PSCF values was very similar to the grid-based of CWT, indicating that the uncertainty in trajectory statistics is determined by the uncertainties in trajectory model outputs. This source oriented method developed here is an information comparable to the one generated with trajectory statistics. Because it is a qualitative source oriented approach that generates information potential source areas that affect concentrations of pollutants at a given receptor.

\section{Recommendations}

In this study, PSCF and CWT analyses were done for only one station in Kenya, ICIPE Mbita. The same analyses could be applied on other two stations namely Nairobi and CRPSM Malindi AERONET stations where the pollutant measurements are available.

In future studies, height considerations with other atmospheric mechanism and chemistry of pollutants would be included in order to integrate them into the current PSCF and WCT methodology.

More data inventory could be improved until up-to-date measurements and obtaining recent trajectories. This would reveal recent changes in the pollution transport trends.

\section{Acknowledgements}

The authors wish to extend their sincere gratitude to the Principal Investigators 
and their staff in establishing and maintaining the AERONET site and for providing online data. We also owe our sincere thanks to the NOAA Air Resources Laboratory for computing back trajectories using the HYSPLIT model. Misiani and Mwai are thankful to the People's Republic of China Government and Kenya Meteorology Department for granting them fellowship and study leave, respectively, without which this work would not have been possible. Yin would like to thank YASS Team of Ethnological Research Innovation for their encouragement and great support during this important project. We also appreciate the insightful suggestions made by the reviewers which helped to improve the clarity and scientific content of the original article.

\section{Conflict of Interest}

No conflict of interest. The authors declare that there are no any competing interests as maybe defined by Advances in Meteorology or any other interests materials that may be perceived to influence the above results and discussion reported in this paper.

\section{References}

[1] Ichoku, C., Remer, L.A. and Eck, T.F. (2005) Quantitative Evaluation and Intercomparison of Morning and afternoon Moderate Resolution Imaging Spectroradiometer (MODIS) Aerosol Measurements from Terra and Aqua. Journal of Geophysical Research, 110, D10S03.

[2] Remer, L.A., et al. (2008) Global Aerosol Climatology from the MODIS Satellite Sensors, Journal of Geophysical Research, 113, D14S07.

https://doi.org/10.1029/2007JD009661

[3] Wang, S., Yu, S., Li, P., Wang, L., Mehmood, K., Liu, W., et al. (2017) A Study of Characteristics and Origins of Haze Pollution in Zhengzhou, China, Based on Observations and Hybrid Receptor Models. Aerosol and Air Quality Research, 17, 513-528. https://doi.org/10.4209/aaqr.2016.06.0238

[4] Moody, J.L. and Galloway, J.N. (1988) Quantifying the Relationship between Atmospheric Transport and the Chemical Composition of Precipitation on Bermuda. Tellus B, 40, 463-479. https://doi.org/10.3402/tellusb.v40i5.16014

[5] Pekney, N., Davidson, C., Zhou, L. and Hopke, P. (2006) Application of PSCF and CPF to PMF-Modeled Sources of $\mathrm{PM}_{2.5}$ in Pittsburgh. Aerosol Science and Technology, 40, 952-961. https://doi.org/10.1080/02786820500543324

[6] Fleming, Z.L., Monks, P.S. and Manning, A.J. (2012) Review: Untangling the Influence of Air-Mass History in Interpreting Observed Atmospheric Composition. Atmospheric Research, 104-105, 1-39. https://doi.org/10.1016/j.atmosres.2011.09.009

[7] Sirois, A. and Bottenheim, J.W. (1995) Use of Backward Trajectories to Interpret the 5-Year Record of PAN and $\mathrm{O}_{3}$ Ambient Air Concentrations at Kejimkujik National Park, Nova Scotia. Journal of Geophysical Research, 100, 2867-2881. https://doi.org/10.1029/94JD02951

[8] Stohl, A. (1998) Computation, Accuracy and Applications of Trajectories: A Review and Bibliography. Atmospheric Environment, 32, 947-966. https://doi.org/10.1016/S1352-2310(97)00457-3

[9] Polissar, A.V., Hopke, P.K., Paatero, P., Kaufmann, Y.J., Hall, D.K., Bodhaine, B.A., 
et al. (1999) The Aerosol at Barrow, Alaska: Long-Term Trends and Source Locations. Atmospheric Environment, 33, 2441-2458.

https://doi.org/10.1016/S1352-2310(98)00423-3

[10] Wang, Y.Q., Zhang, X.Y. and Arimoto, R. (2006) The Contribution from Distant Dust Sources to the Atmospheric Particulate Matter Loadings at Xi'an, China during Spring. Science of the Total Environment, 368, 875-883.

https://doi.org/10.1016/j.scitotenv.2006.03.040

[11] Xin, Y., Wang, G. and Chen, L. (2016) Identification of Long-Range Transport Pathways and Potential Sources of $\mathrm{PM}_{10}$ in Tibetan Plateau Uplift Area: Case Study of Xining, China in 2014. Aerosol and Air Quality Research, 16, 1044-1054. https://doi.org/10.4209/aaqr.2015.05.0296

[12] Karaca, F. and Camci, F. (2010) Distant Source Contributions to $\mathrm{PM}_{10}$ Profile Evaluated by SOM Based Cluster Analysis of Air Mass Trajectory Sets. Atmospheric Environment, 44, 892-899. https://doi.org/10.1016/j.atmosenv.2009.12.006

[13] Li, D., Liu, J., Zhang, J., Gui, H., Du, P., Yu, T., et al. (2017) Identification of Long-Range Transport Pathways and Potential Sources of $\mathrm{PM}_{2.5}$ and $\mathrm{PM}_{10}$ in Beijing from 2014 to 2015. Journal of Environmental Sciences (China), 56, 214-229. https://doi.org/10.1016/j.jes.2016.06.035

[14] Zachary, M., Yin, L. and Zacharia, M. (2018) Aerosol Optical Depth Pathways and Sources, Lake Victoria Basin. OALib, 5, 1-11.

https://doi.org/10.4236/oalib.1104393 